\title{
Comparison of the Length of Stay and Medical Expenditures among Japanese Hospitals for Type 2 Diabetes Treatments: The Box-Cox Transformation Model under Heteroscedasticity
}

\author{
Kazumitsu Nawata1, Koichi Kawabuchi² \\ ${ }^{1}$ Graduate School of Engineering, University of Tokyo, Tokyo, Japan \\ ${ }^{2}$ Graduate School of Medical and Dental Sciences, Tokyo Medical and Dental University, Tokyo, Japan \\ Email: nawata@tmi.t.u-tokyo.ac.jp, kawabuchi.hce@tmd.ac.jp
}

Received 8 December 2015; accepted 15 January 2016; published 18 January 2016

Copyright (C) 2016 by authors and Scientific Research Publishing Inc.

This work is licensed under the Creative Commons Attribution International License (CC BY).

http://creativecommons.org/licenses/by/4.0/

cc) (i)

\section{Abstract}

In this paper, we analyzed length of stay (LOS) in hospitals and medical expenditures for type 2 diabetes patients. LOS was analyzed by the power Box-Cox transformation model when variances differed among hospitals. We proposed a new test and consistent estimator. We rejected the homoscedasticity of variances among hospitals, and then analyzed the LOS of 12,666 type 2 diabetes patients hospitalized for regular medical treatments collected from 60 general hospitals in Japan. The variables found to affect LOS were age, number of comorbidities and complications, introduced by another hospital, one-week hospitalization, 2010 revision, specific-hospitalization-period (SHP), and principal diseases E11.5, E11.6 and E11.7. There were surprisingly large differences in ALOS among hospitals even after eliminating the influence of characteristics and conditions of patients. We then analyzed daily medical expenditure (DME) by the ordinary least squares methods. The variables that affected DME were LOS, number of comorbidities and complications, acute hospitalization, hospital's own outpatient, season, introduced by another hospital, one-week hospitalization, 2010 revision, SHP, time trend, and principal diseases E11.2, E11.4 and E117. The DME did not decrease after the SHP. After eliminating the influences of characteristics and conditions of patients, the differences among hospitals were relatively small, $12 \%$ of the overall average. LOS is the main determinant of medical expenditures, and new incentives to reduce LOS are needed to control Japanese medical expenditures. Since at least $99 \%$ of patients require medical care after leaving the hospital, systems that take proper care of patients for long periods of time after hospitalization are absolutely necessary for efficient treatment of diabetes. 


\section{Keywords}

\section{Type 2 Diabetes, Medical Expenditure, Length of Hospital Stay, Cox-Box Transformation,} Heteroscedasticity

\section{Introduction}

In October 2015, the Ministry of Health, Labour and Welfare [1] announced that Japanese medical expenditures for fiscal year (FY, the Japanese fiscal year is April-March) 2013 exceeded 40 trillion yen (40.06 trillion yen), an increase of 0.85 trillion yen or $2.2 \%$ from previous years. Japan has had a mandatory insurance system since 1961. In FY 2013, public expenditures were 15.53 trillion yen (10.36 trillion from the central and 5.16 trillion from local governments), public insurance premiums were 19.52 trillion yen (8.12 trillion from employers and 11.40 trillion from the insured), and direct expenditures by patients were just 4.71 trillion yen or $11.7 \%$ of the total. Public expenditures increased by 0.39 trillion yen over the previous year, reaching $38.8 \%$ of total medical expenditure. Meanwhile, at the end of FY 2014, the Japanese long-term financial deficit reached 1009 trillion yen (809 trillion from central and 201 trillion from local governments) or 205\% of the Japanese Gross Domestic Product (GDP) [2]. Thus, controlling medical expenditures by efficient use of medical resources is an urgent political issue for sustaining the medical insurance system.

Among various diseases, medical expenditure for cataract was 1.21 trillion yen, one of the most expensive disease [1]. The cost of diabetes, however, has become a worldwide problem. The International Diabetes Federation (IDF) [3] reported that total world health expenditure for this disease was $\$ 612$ billion in 2014. Moreover, diabetes can cause serious complications such as vision loss, kidney disease (nephropathy), heart failure, and stroke [4] [5]. If the costs of taking care of the comorbidities and complications of diabetes were included, the medical costs of diabetes would likely be much higher. The Public Health Agency of Canada [6] has reported that the "direct health care costs may be as much as 4.5 times higher than when looking at diabetes alone". Lesniowska et al. [7] found that the costs of treating complications in Poland were more than five times those of hospital diabetes treatment. Chereches et al. [8] reported that comorbid depression increased diabetes-related costs in Romania. Yeaw [9] analyzed the costs of complications in the United States in cohorts based on age and diabetes type and found that the cost of renal diseases, lactic acidosis and peritoneal dialysis were highest. Zhuo et al. [10] estimated that the discounted excess lifetime medical costs for people with diabetes in the United States were $\$ 124,600$, $\$ 91,200, \$ 53,800$ and $\$ 35,900$ when diabetes was diagnosed at age $40,50,60$ and 65 , respectively. Condliffe, Parasuraman and Pollack [11] reported that medical expenditures for diabetes patients with comorbid hypertension and obesity were significantly higher than those of patients without these comorbidities. Yesudian et al. [12] summarized the literature about the economic burden of diabetes in India. In addition to the medical costs, diabetes reduces the labor supply and the productivity of patients. Dall et al. [13] reported that the national economic burden of pre-diabetes and diabetes in the United States reached \$218 billion in 2007, \$153 billion in higher medical costs and \$65 billion in reduced productivity. More recently, the American Diabetes Association (ADA) [14] estimated that in 2012, the total cost of diabetes in the United States was $\$ 245$ billion. Of this total, $\$ 69$ billion were indirect costs related to reductions in productivity; this was broken down further as inability to participate in the labor force (2.7 billion), inability to work as a result of disease-related disability (21.6 billion), and lost productive capacity due to early mortality (18.5 billion). The Public Health Agency of Canada [6] found that the indirect costs of diabetes amounted to \$1.7 billion (Canadian) in 2000. Other reports [15]-[19] suggest that diabetes and diabetes-related complications reduced employment, length of working days, and wage rates. All studies lead to the same conclusion: that the true cost of diabetes is much higher than the direct cost.

In Japan, a new inclusive payment system based on the Diagnosis Procedure Combination (DPC) was introduced in April 2003. The system is called the DPC/PDPS (per diem payment system). As of April 2015, it was estimated that a total of 1580 hospitals had joined the DPC/PDPS, and an additional 266 hospitals were preparing to join (hereafter DPC hospitals) [20]. The DPC hospitals have a total of 520,570 beds. This means that they comprise about $25 \%$ of the 7528 general hospitals and $58 \%$ of the total number of hospital beds $(899,385)$ in Japan. Since DPC hospitals must computerize their medical information, we now have access to large-scale 
medical datasets.

The IDF [21] reported that $90 \%$ or more of diabetics have type 2 diabetes. (Diabetes can be classified as type 1 or type 2; for details, see ADA [22].) Nawata and Kawabuchi [23] [24] studied the length of stay (LOS) in hospitals for type 2 patients who joined educational programs for lifestyle improvement rather than treatment (hereafter educational hospitalization). They found a large variation among hospitals in average length of stay (ALOS), and that ALOS at some hospitals was unreasonably long even after eliminating the influence of patient characteristics. These researchers also evaluated the daily medical expenditure (DME) per patient [24]. Unlike ALOS, the variation in average daily medical expenditures (ADME) among hospitals were rather small, with the difference between the largest and smallest being just $15 \%$ of the overall average. However, in their study, type 2 diabetes patients who were hospitalized for regular medical treatments (hereafter, regular patients) were not analyzed. Since treatments for regular patients may vary depending on the conditions of patients, heterogeneity among regular patients is considered to be much larger than in the educational hospitalization cases. In our dataset, regular patients represented about two thirds of type 2 diabetes patients, and their treatment constituted over $70 \%$ of expenditures.

In this paper, we analyzed LOS and DME of regular patients. LOS was analyzed by the Box-Cox [25] transformation model (BC model), taking into account variance among hospitals. The maximum likelihood estimator (BC MLE), which maximizes the likelihood function under the normality assumption, has large biases of the BC MLE when heterogeneity exists in variances [26]. For LOS in particular, variances often differ greatly among hospitals, even after controlling for the characteristics of diseases, treatments and patients. Nawata [27] proposed a robust estimator that is consistent under heteroscedasticity. However, since the variance of the estimator is rather large, we sometimes failed to detect heteroscedasticity. Therefore, we propose a test and new estimator for heteroscedastic cases. Next, we analyzed the LOS of regular patients without any operations by the proposed methods. We used the DPC dataset of 12,666 patients with DPC code 10070xxxxx0x collected from 60 DPC hospitals in Japan. We then evaluated the daily expenditures by the ordinary least squares (OLS) method.

\section{Models for the Analysis of LOS}

For the analysis of cost-effectiveness in diabetes, cohort-study-type models are often used [28]. However, it is necessary to consider various risk factors for diabetes, including related complications and comorbidities. Watson et al. [29] reviewed over 100 studies and concluded that, "None of the identified papers included all of these features” ([29], p. 250). Therefore, we employed regression-type models. The distribution of LOS of regular patients is shown in Figure 1. The distribution shows a heavy tail on the right side. In analyzing medical costs with a multiple regression model, Sittig, Friedel and Wasem [30] also found that costs were not normally distributed and were skewed to the right, as in this study. They used the log transformation. In this paper, we used the BC model for the analysis of LOS. The BC transformation includes the log transformation. Since the distribution was not skewed, we used the OLS for the analysis of the DME.

\subsection{BC Model and BC MLE}

Suppose that the LOS of patient $j$ in hospital $i$ is given by the BC model:

$$
\begin{aligned}
& z_{i j}=\left(t_{i j}^{\lambda}-1\right) / \lambda \text { if } \lambda \neq 0, \quad z_{i j}=\log \left(t_{i j}\right) \text { if } \lambda=0, \\
& z_{i j}=x_{i j}^{\prime} \beta+u_{i j} \quad i=1,2, \cdots, k, j=1,2, \cdots, n_{i}
\end{aligned}
$$

where $t_{i j}$ is LOS, $\lambda$ is the transformation parameter, $x_{i j}$ and $\beta$ are the vectors of the explanatory variables and coefficients, $k$ is the number of hospitals, $n_{i}$ is the number of patients in hospital $i$, and $n=\sum_{i} n_{i}$. Here

$u_{i j}$ is assumed to follow the normal distribution with mean 0 and variance $\sigma_{i j}^{2}$. Let $\theta^{\prime}=\left(\lambda, \beta^{\prime}, \sigma^{2}\right)$. The BC likelihood function under the normality assumption of the error terms is given by

$$
\log L(\theta)=\sum_{i, j}\left[\log \phi\left\{\left(z_{i j}-x_{i j}^{\prime} \beta\right) / \sigma\right\}-\log \sigma\right]+(\lambda-1) \sum_{i, j} \log t_{i j},
$$

where $\phi$ is the probability density function of the standard normal assumption, and $\sigma^{2}$ is the variance of $u_{i j}$ under homoscedasticity. The BC MLE maximizes the likelihood function given by Equation (2), and is consistent if the error terms are homoscedastic and the "small $\sigma$ " assumption [31] is satisfied. 


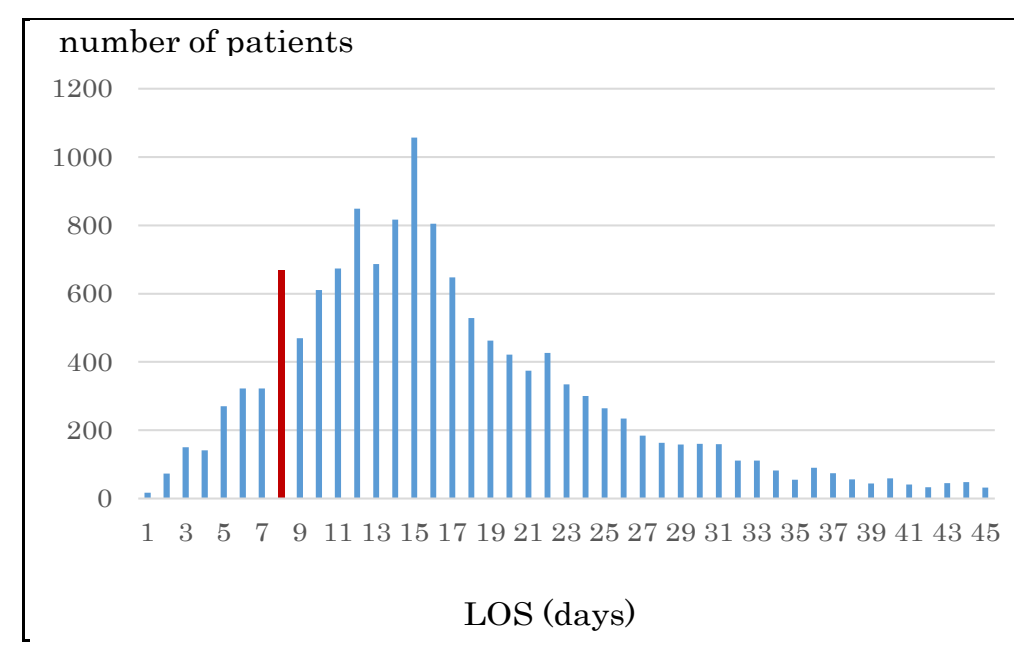

Figure 1. Distribution of LOS of regular patients.

\subsection{Nawata's Estimator and the Test for the "Small $\sigma$ " Assumption}

Nawata [32] proposed a semiparametric estimator (hereafter, N-estimator), obtained by

$$
\begin{aligned}
G(\theta)= & -\frac{1}{\sigma^{2} \lambda} \sum_{i, j}\left[\left\{\frac{\left(\lambda x_{i j}^{\prime} \beta+1\right) \log \left(\lambda x_{i j}^{\prime} \beta+1\right)}{\lambda}-x_{i j}^{\prime} \beta\right\}\left(z_{i j}-x_{i j}^{\prime} \beta\right)+\log \left(\lambda x_{i j}^{\prime} \beta+1\right)\left(z_{i j}-x_{i j}^{\prime} \beta\right)^{2}+\frac{\lambda\left(z_{i j}-x_{i j}^{\prime} \beta\right)^{3}}{\lambda x_{i j}^{\prime} \beta+1}\right] \\
& +\sum_{i, j}\left\{\frac{1}{\lambda} \log \left(\lambda x_{i j}^{\prime} \beta+1\right)+\frac{\left(z_{i j}-x_{i j}^{\prime} \beta\right)}{\lambda x_{i j}^{\prime} \beta+1}\right\}=0,
\end{aligned}
$$

$\sum_{i, j} x_{i j}\left(z_{i j}-x_{i j}^{\prime} \beta\right)=0$, and $\sigma^{2}=\sum_{i, j} \frac{\left(z_{i j}-x_{i j}^{\prime} \beta\right)^{2}}{n}$.

These equations are available by the approximation of the $\partial \log L / \partial \theta$. Using the BC MLE and N-estimator, we can conduct the test for the "small $\sigma$ " assumption (the null hypothesis is that the "small $\sigma$ " assumption holds) by the Hausman test [33]. For details, see Nawata and Kawabuchi [23] [24].

\subsection{A Test for Homoscedasticity}

The N-estimator cannot be consistent under heteroscedasticity. Nawata [27] proposed a consistent estimator even under heteroscedasticity based on the third-moment restriction. However, as the result of a Monte Carlo study showed, the variances of the estimators were rather large [27], and we cannot sometimes reject the null hypothesis of homoscedasticity even if the error terms are heteroscedastic. In other words, the power of the Hausman test based on Nawata's [27] estimator may not be high in some cases. Here, we propose a new test. The advantage of the test is that the residuals of the BC model are directly used and we do not need an alternative estimator unlike the Hausman test. The null hypothesis is that the error terms are homoscedastic, and $\sigma_{i j}^{2}=\sigma_{0}^{2}$ for any $i$ and $j$. Note that we used the residuals of the BC MLE if the "small $\sigma$ " assumption were accepted, and the N-estimator otherwise in the previous test. Let $\left\{e_{i}\right\}$ be residuals of the BC model and $\left(\lambda_{0}, \beta_{0}^{\prime}\right)$ be true parameter values. Then

$$
\begin{aligned}
e_{i j} & =\hat{z}_{i j}-x_{i j}^{\prime} \hat{\beta}=u_{i j}+\left(\frac{t_{i j}^{\hat{\lambda}}-1}{\hat{\lambda}}-\frac{t_{i j}^{\lambda_{0}}-1}{\lambda_{0}}\right)+x_{i j}^{\prime}\left(\beta_{0}-\hat{\beta}\right) \\
& =u_{i j}+\psi_{i j}\left(\lambda_{0}\right)\left(\hat{\lambda}-\lambda_{0}\right)+x_{i j}^{\prime}\left(\beta_{0}-\hat{\beta}\right)+o_{p}(1 / \sqrt{n})
\end{aligned}
$$

where $\hat{z}_{i j}=\left(t_{i j}^{\hat{\lambda}}-1\right) / \hat{\lambda}$ and $\psi_{i j}(\lambda)=\frac{\mathrm{d} z_{i j}}{\mathrm{~d} \lambda}=\frac{1}{\lambda}\left(-z_{i j}+t_{i j}^{\lambda} \log t_{i j}\right)$. Therefore, 


$$
e_{i j}^{2}=u_{i j}^{2}+2 \psi_{i j}\left(\lambda_{0}\right)\left(\hat{\lambda}-\lambda_{0}\right) u_{i j}+x_{i j}^{\prime}\left(\beta_{0}-\hat{\beta}\right) u_{i j}+o_{p}(1 / \sqrt{n}) .
$$

Under the null hypothesis,

$$
\begin{aligned}
& \sqrt{n} \sum_{i, j}\left(f_{1 i j}-f_{2 i j}\right) e_{i j}^{2}=\sqrt{n} \sum_{i, j}\left(f_{1 i j}-f_{2 i j}\right)\left(e_{i j}^{2}-\sigma_{0}^{2}\right) \\
& =\sqrt{n} \sum_{i, j}\left(f_{1 i j}-f_{2 i j}\right)\left(u_{i j}^{2}-\sigma_{0}^{2}\right)+2 \sqrt{n}\left(\hat{\lambda}-\lambda_{0}\right) \sum_{i j}\left(f_{1 i j}-f_{2 i j}\right) \psi_{i j}\left(\lambda_{0}\right) u_{i j}+\sqrt{n}\left(\beta_{0}-\hat{\beta}\right)^{\prime} \sum_{i, j} x_{i j}^{\prime} u_{i j}+o_{p}(1) \\
& =\sqrt{n} \sum_{i, j}\left(f_{1 i j}-f_{2 i j}\right)\left(u_{i j}^{2}-\sigma_{0}^{2}\right)+2 \sqrt{n}\left(\hat{\lambda}-\lambda_{0}\right) a+o_{p}(1)
\end{aligned}
$$

where $f_{1 i j}=\frac{\log \left(\lambda x_{i j}^{\prime} \beta+1\right)}{\sum_{i, j} \log \left(\lambda x_{i j}^{\prime} \beta+1\right)}$ and $f_{2 i j}=\frac{1}{n}$. From Equation (6), we get

$$
\begin{gathered}
\sqrt{n} \sum_{i, j}\left(f_{1 i j}-f_{2 i j}\right) e_{i j}^{2} / \sqrt{V_{1}} \rightarrow N(0,1) \\
V_{1}=\lim _{n \rightarrow \infty}\left[n \sum_{i, j}\left(f_{1 i j}-f_{2 i j}\right)^{2}\left(E u_{i j}^{4}-\sigma^{4}\right)+4 a^{2} n V(\hat{\lambda})+4 a E\left\{\sqrt{n}\left(\hat{\lambda}-\lambda_{0}\right) \sqrt{n} \sum_{i, j}\left(f_{1 i j}-f_{2 i j}\right)\left(u_{i j}^{2}-\sigma_{0}^{2}\right)\right\}\right],
\end{gathered}
$$

and

$$
a=p \lim _{n \rightarrow \infty} \sum_{i j}\left(f_{1 i j}-f_{2 i j}\right) \psi_{i j}\left(\lambda_{0}\right) u_{i j},
$$

under the null hypothesis, and we can use $t=\sqrt{n} \sum_{i, j}\left(f_{1 i j}-f_{2 i j}\right) e_{i j}^{2} / \sqrt{\hat{V}_{1}}$ as the test statistic where $\hat{V}_{1}$ is the estimator of $V_{1}$. The calculation of $V_{1}$ may not be easy, and we get the following formula in the test

$$
\left|\sqrt{V_{2}}-\sqrt{V_{3}}\right| \leq \sqrt{V_{1}} \leq \sqrt{V_{2}}+\sqrt{V_{3}}, V_{2}=n \sum_{i, j}\left(f_{1 i j}-f_{2 i j}\right)^{2}\left(E u_{i j}^{4}-\sigma^{4}\right), V_{3}=4 a^{2} n V(\hat{\lambda}) .
$$

When the BC MLE is used, $V_{2}=\left(E u_{i j}^{4}-\sigma^{4}\right)=2 \sigma^{4}$ from the moment of the normal distribution.

\subsection{A New Consistent Estimator under Heteroscedasticity}

If the null hypothesis of homoscedasticity is accepted, we can use the BC MLE or N-estimator. When it is rejected, we modified Equation (3) and replaced $G(\theta)$ with

$$
H(\theta)=-\frac{1}{\sigma^{2} \lambda} \sum_{i, j}\left[\left\{\frac{\left(\lambda x_{i j}^{\prime} \beta+1\right) \log \left(\lambda x_{i j}^{\prime} \beta+1\right)}{\lambda}-x_{i j}^{\prime} \beta\right\}\left(z_{i j}-x_{i j}^{\prime} \beta\right)+\frac{\lambda\left(z_{i j}-x_{i j}^{\prime} \beta\right)^{3}}{\lambda x_{i j}^{\prime} \beta+1}\right]+\sum_{i, j} \frac{\left(z_{i j}-x_{i j}^{\prime} \beta\right)}{\lambda x_{i j}^{\prime} \beta+1}=\sum_{i, j} h_{i j}(\theta)=0 .
$$

$H\left(\theta_{0}\right)$ does not depend on the second moments of error terms, $E\left\{H\left(\theta_{0}\right)\right\}=0$ even under heteroscedasticity where $\theta_{0}=\left(\lambda_{0}, \beta_{0}, \bar{\sigma}^{2}\right)$ and $\bar{\sigma}^{2}=\lim _{n \rightarrow \infty} \frac{1}{n} \sum_{i, j} \sigma_{i j}^{2}$. Therefore, from the same argument of Nawata [27] [32], there exists a consistent estimator of $\lambda$ and $\beta$ among the roots if $G(\theta)$ is replaced by $H(\theta)$ in Equation (3). Let $\hat{\theta}_{M}=\left(\hat{\lambda}_{M}, \hat{\beta}, \hat{\sigma}_{M}\right)$ be the consistent root. The asymptotic distribution of this estimator $\hat{\theta}_{M}$ is given by

$$
\sqrt{n}\left(\hat{\theta}_{M}-\theta_{0}\right) \rightarrow N\left[0, A^{-1} B\left(A^{\prime}\right)^{-1}\right],
$$

where $A=-\left.p \lim _{n \rightarrow \infty} \frac{1}{n} \frac{\partial \xi}{\partial \theta}\right|_{\theta_{0}}, \xi(\theta)^{\prime}=\left[H(\theta), \sum_{i . j}\left(z_{i j}-x_{i j}^{\prime} \beta\right) x_{i j}^{\prime}, \sum_{i . j}\left(z_{i j}-x_{i j}^{\prime} \beta\right)^{2}-n \bar{\sigma}^{2}\right]$,

$$
B=\lim _{n \rightarrow \infty} \frac{1}{n} \sum_{i, j} E\left[\left.\left.\frac{\partial \varsigma_{i j}}{\partial \theta}\right|_{\theta_{0}} \frac{\partial \varsigma_{i j}}{\partial \theta^{\prime}}\right|_{\theta_{0}}\right] \text {, and } \varsigma_{i j}\left(\theta_{0}\right)^{\prime}=\left[h_{i j}\left(\theta_{0}\right), x_{i j}^{\prime} u_{i j},\left(u_{i j}^{2}-\bar{\sigma}^{2}\right)\right] \text {. }
$$




\section{Evaluations of the LOS and DME}

In this section, we analyze the LOS of regular type 2 diabetic patients by the proposed method and the DME per patient by the OLS method.

\subsection{Data}

The data used in this study were collected by the Department of Health Care Economics at the Tokyo Medical and Dental University from over 100 hospitals; the sample period was from July 2008 to March 2012. The data included patients' LOS, medical expenditures, age, gender, health-related conditions and medical treatments. For details, see Nawata and Kawabuchi [23]. The original dataset included 27,861 patients, and 22,430 patients (80\%) were classified under the DPC code 100070xxxxxx0x (type 2 diabetes patient without diabetic ketoacidosis and secondary diseases). The ALOS and average medical expenditure (AME) for these patients were 17.4 days and 461,431 yen, respectively. This means that $77 \%$ of medical expenditures for diabetes were for these patients. As in the previous study [24], we only used the data of patients: 1) who were treated in clinical departments that mainly treat diabetes; and 2) whose principle disease was diabetes. Of the 21,603 patients who satisfied these criteria, 14,193 were regular patients. Diabetes can cause complications that require serious operations. It is natural that LOS would become longer and medical expenditures higher for these patients. Therefore, we excluded 932 patients who had received operations (ALOS and AME for patients with operations were 28.5 days and 882,378 yen, respectively). Finally, we used a data set of 12,666 patients in 60 hospitals (Hp1-60) with more than 60 regular patients to evaluate the effects of patients.

Table 1 shows LOS and medical expenditure by hospital. For all 12,666 patients, ALOS was 18.1 days with a standard deviation (SD) of 12.7 days. The AME was 461,680 yen with a SD of 273,253 yen. In the case of educational hospitalization, the ALOS was 13.7 days with a SD of 6.7 days, and the AME was 370,336 yen with a SD of 152,895 yen for 6,178 patients. Therefore, the ALOS was 4.4 days longer and AME was 91,344 yen higher for regular patients than for those with an educational hospitalization [24]. Moreover, the coefficients of variation (=SD/average) became 70\% for LOS and 59\% for medical expenditures. The coefficients of variation were $49 \%$ and $41 \%$ for the educational hospitalizations. This means that heterogeneity of regular patients was larger than that of educational hospitalization, as expected.

The maximum ALOS by hospital was 37.6 days (hp50) and the minimum was 10.0 days (hp42). The maximum was thus 3.8 times larger than the minimum, with a difference of 27.6 days. The maximum SD by hospital was 28.4 days (hp21), and the minimum was 4.7 days (hp52). This maximum was six times larger than the minimum and the variances were quite different among hospitals. This implies the importance of the proposed model, which takes into account the heteroscedasticity of the variances.

Figure 2 shows the relationship between the ALOS and AME by hospital. The correlation coefficient was 0.984, and there was an almost linear relation between these two variables. This implies that despite large heterogeneity among patients, ALOS was the largest determinant of AME.

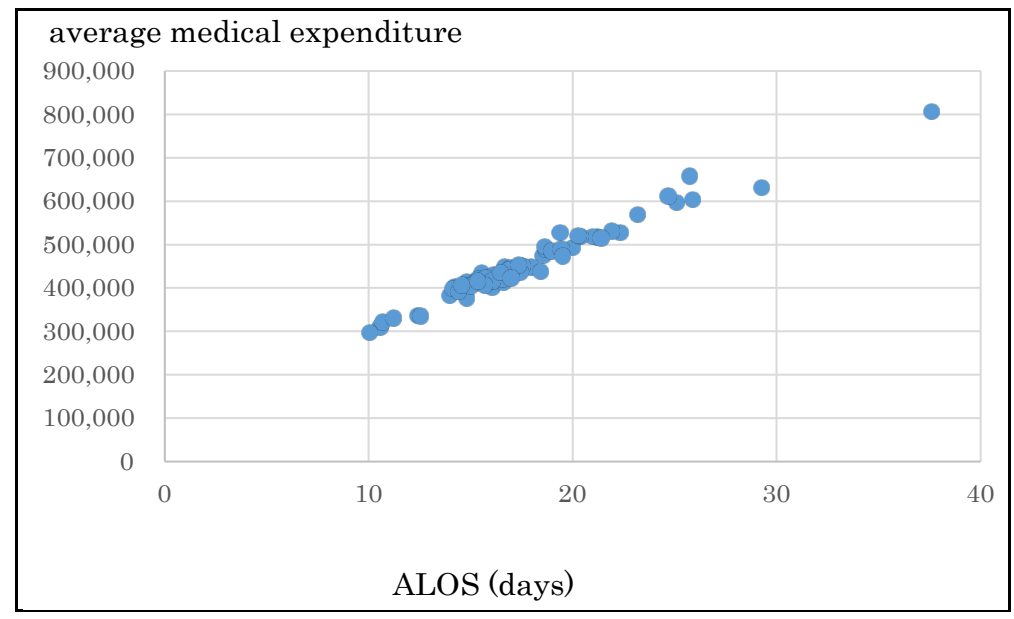

Figure 2. ALOS and average medical expenditures by hospital. 
Table 1. Length of stay and medical expenditure by hospital.

\begin{tabular}{|c|c|c|c|c|c|c|c|c|c|c|c|}
\hline \multirow{2}{*}{ HP } & \multirow{2}{*}{$\mathrm{N}$} & \multicolumn{2}{|c|}{ LOS (days) } & \multicolumn{2}{|c|}{ ME (yen) } & \multirow{2}{*}{ HP } & \multirow{2}{*}{$\mathrm{N}$} & \multicolumn{2}{|c|}{ LOS (days) } & \multicolumn{2}{|c|}{ ME (yen) } \\
\hline & & ALOS & SD & AME & SD & & & ALOS & SD & AME & SD \\
\hline HP1 & 582 & 14.79 & 5.85 & 413,632 & 144,371 & HP32 & 192 & 16.85 & 9.83 & 442,586 & 219,745 \\
\hline HP2 & 137 & 18.55 & 13.83 & 474,460 & 301,932 & HP33 & 149 & 15.17 & 8.55 & 412,000 & 185,321 \\
\hline HP3 & 85 & 17.94 & 15.11 & 449,164 & 317,935 & HP34 & 149 & 10.67 & 4.96 & 322,364 & 143,331 \\
\hline HP4 & 63 & 15.54 & 8.99 & 435,237 & 206,362 & HP35 & 62 & 17.40 & 8.98 & 436,615 & 181,931 \\
\hline HP5 & 89 & 25.72 & 20.51 & 658,025 & 439,181 & HP36 & 212 & 14.38 & 8.90 & 391,749 & 193,203 \\
\hline HP6 & 254 & 14.70 & 6.31 & 406,213 & 141,270 & HP37 & 259 & 15.81 & 6.46 & 413,243 & 146,484 \\
\hline HP7 & 99 & 25.10 & 25.15 & 597,842 & 555,042 & HР38 & 304 & 17.35 & 9.21 & 453,310 & 207,938 \\
\hline HP8 & 252 & 16.63 & 9.43 & 450,692 & 334,735 & HР39 & 294 & 23.15 & 14.77 & 569,587 & 358,668 \\
\hline HP9 & 148 & 21.22 & 9.92 & 517,550 & 209,554 & HP40 & 341 & 12.52 & 7.75 & 335,680 & 175,104 \\
\hline HP10 & 70 & 18.40 & 11.62 & 438,506 & 224,096 & HP41 & 357 & 22.31 & 10.70 & 527,369 & 232,023 \\
\hline HP11 & 102 & 15.35 & 12.71 & 421,123 & 292,665 & HP42 & 653 & 15.71 & 5.84 & 424,447 & 137,315 \\
\hline HP12 & 302 & 16.11 & 6.93 & 431,296 & 162,428 & HP43 & 89 & 14.98 & 6.42 & 404,746 & 154,791 \\
\hline HP13 & 149 & 16.03 & 7.36 & 402,396 & 133,737 & HP44 & 186 & 16.04 & 7.35 & 416,456 & 161,017 \\
\hline HP14 & 429 & 24.67 & 11.59 & 612,452 & 245,115 & HP45 & 330 & 19.99 & 10.29 & 493,362 & 217,380 \\
\hline HP15 & 193 & 14.77 & 6.69 & 377,203 & 140,015 & HP46 & 136 & 19.41 & 13.63 & 489,587 & 299,087 \\
\hline HP16 & 98 & 18.64 & 12.41 & 489,848 & 271,582 & HP47 & 229 & 15.66 & 10.30 & 407,329 & 232,307 \\
\hline HP17 & 542 & 10.54 & 7.43 & 309,743 & 164,012 & HP48 & 177 & 16.47 & 10.60 & 435,584 & 234,179 \\
\hline HP18 & 124 & 14.20 & 6.04 & 402,431 & 148,693 & HP49 & 603 & 16.97 & 8.78 & 423,653 & 181,434 \\
\hline HP19 & 70 & 16.59 & 12.18 & 414,280 & 233,975 & HP50 & 557 & 37.57 & 24.83 & 807,833 & 484,304 \\
\hline HP20 & 79 & 12.37 & 7.40 & 337,624 & 158,109 & HP51 & 179 & 21.88 & 19.35 & 531,286 & 422,577 \\
\hline HP21 & 80 & 29.24 & 28.35 & 632,467 & 622,123 & HP52 & 240 & 10.03 & 4.74 & 297,370 & 115,368 \\
\hline HP22 & 138 & 13.94 & 4.95 & 383,960 & 123,768 & HP53 & 268 & 20.38 & 10.94 & 518,470 & 243,989 \\
\hline HP23 & 64 & 18.63 & 8.37 & 496,006 & 187,280 & HP54 & 196 & 14.55 & 6.23 & 406,779 & 152,333 \\
\hline HP24 & 181 & 16.96 & 13.57 & 447,201 & 299,459 & HP55 & 102 & 21.37 & 10.05 & 515,697 & 211,656 \\
\hline HP25 & 177 & 18.94 & 11.72 & 485,520 & 261,974 & HP56 & 229 & 15.34 & 10.05 & 416,528 & 228,015 \\
\hline HP26 & 244 & 15.55 & 7.33 & 410,726 & 168,783 & HP57 & 177 & 20.24 & 9.40 & 520,557 & 280,607 \\
\hline HP27 & 269 & 16.53 & 12.87 & 421,123 & 284,123 & HP58 & 70 & 11.21 & 6.08 & 331,358 & 152,516 \\
\hline HP28 & 93 & 14.11 & 8.31 & 398,494 & 200,704 & HP59 & 208 & 25.86 & 13.25 & 604,269 & 313,967 \\
\hline HP29 & 75 & 19.37 & 20.51 & 528,224 & 555,561 & HP60 & 99 & 19.49 & 14.71 & 473,631 & 314,834 \\
\hline НР30 & 254 & 17.51 & 10.07 & 451,452 & 223,114 & All & 12666 & 18.05 & 12.66 & 461,680 & 273,253 \\
\hline HP31 & 177 & 20.98 & 10.80 & 518,968 & 230,641 & & & & & & \\
\hline
\end{tabular}




\subsection{Evaluation of LOS}

We chose the following as explanatory variables. The Female dummy (1: female, 0 : male) was used for gender. The proportion of female patients was $42.3 \%$. Since LOS tends to increase with patient age, we used Age as an explanatory variable. The average age of the patients was 63.8 , and the standard deviation was 13.9 years. Japan has a mandatory health insurance system, and the percentage of medical fees paid by patients changed at age 70 in the sample period (30\% for younger than $70 ; 10 \%$ for 70 or over). So, an Age 70 (1: 70 or over, 0: otherwise) dummy was also added. Other explanatory variables representing the conditions of patients included: Comorbidities (number of comorbidities), Complications (number of complications), Acute Hospitalization dummy (acute hospitalization: 1, otherwise: 0), Outpatient dummy (outpatient of the same hospital before hospitalization: 1 , otherwise: 0), Introduction dummy (introduced by another hospital: 1, otherwise: 0 ), and Home dummy (1: returned to home: 1 , otherwise: 0 ). Among our study subjects, $14.6 \%, 15.7 \%, 15.1 \%$ and $39.4 \%$ of patients had 1 , 2, 3 and 4 comorbidities, respectively, while $16.1 \%, 10.6 \%, 7.0 \%$ and $10.2 \%$ of patients had 1, 2, 3 and 4 complications, respectively. The proportions of acute hospitalization patients, outpatients of the same hospital before hospitalization, patients introduced by another hospital, and patients who returned home were $18.9 \%, 80.1 \%$, $38.2 \%$, and $77.7 \%$, respectively. To evaluate seasonal effects we added Winter (December to February) and Summer (July and August) dummies. Since the DPC/PDPS was revised in April 2010, an after 2010 dummy (after April, 2010: 1, otherwise: 0) was used. As shown in Figure 1, many patients were discharged from hospitals on the eighth day (after one week of hospitalization); hence, we added the One Week dummy (discharged on the eight day: 1, otherwise: 0). If the LOS exceeds the Specific-Hospitalization-Period (SHP, 29 days in this case) determined by the DPC/PDPS, the medical payment becomes a conventional fee-for-service system. Therefore, we added the Over SHP dummy (LOS is over the SHP: 1, otherwise: 0). For these variables, $55.0 \%$ of patients were after April 2010, 5.0\% were discharged on the eighth day, and 11.0\% stayed over the SHP.

To evaluate the time trend that may represent the progress of medical technologies, Time (number of months from July 2008) was used. For more specific classification of the principal disease, the International Disease Classification version 10 (ICD-10) was used. The ICD-10 classifies type 2 diabetes by complications. We used the E11.2-E11.7 dummies based on E11.9 (without complications). Among patients, 5.9\% were classified under E11.2 (with kidney complications), 7.8\% were classified under E11.3 (with ophthalmic complications), 5.2\% were classified under E11.4 (with neurological complications), 0.8\% were classified under E11.5 (with circulatory complications), 13.1\% were classified under E11.6 (with other specified complications), and 32.1\% were classified under E11.7 (with multiple complications). To evaluate the effects of hospitals, we added 60 hospital dummies and did not use the constant term.

As a result, Equation (1) becomes:

$$
\begin{aligned}
x_{i j}^{\prime} \beta= & \beta_{1} \text { Female }+\beta_{2} \text { Age }+\beta_{3} \text { Age } 70+\beta_{6} \text { Comorbidities }+\beta_{5} \text { Complications } \\
& +\beta_{6} \text { Acute Hospitalization }+\beta_{7} \text { Outpatient }+\beta_{8} \text { Introduction }+\beta_{9} \text { Home } \\
& +\beta_{10} \text { One Week }+\beta_{13} \text { Over SHP }+\sum_{\ell} \beta_{\ell} \text { ICD-10 dummy }+\sum_{i} \beta_{i} \text { i-th Hospital dummy }
\end{aligned}
$$

We first tested the "small $\sigma$ " assumption. The estimates of $\lambda$ were 0.3537 for the BC MLE and 0.3785 for the $\mathrm{N}$-estimator. The value of the test statistic was $t=(0.3537-0.3785) / 0.0338=1.775$ and the null hypothesis was accepted at the 5\% level. Therefore, we used the residuals of the BC MLE in the test for heteroscedasticity. We got $\sqrt{n} \sum_{i, j}\left(f_{1 i j}-f_{2 i j}\right) e_{i j}^{2}=0.0398$ and $\sqrt{V_{1}} \leq \sqrt{V_{2}}+\sqrt{V_{3}}=0.0121$, and the value of the test statistic was $t \geq 3.281$. The null hypothesis was rejected at the $1 \%$ level; thus, we could not use the BC MLE and had to use the newly proposed estimator.

The estimation results are presented in Table 2 . The estimate of $\lambda$ was 0.4824 , which was sufficiently larger than that of the BC MLE. This coincides with the results of the Monte Carlo study [27], where the BC MLE underestimated $\lambda$ under heteroscedasticity. The results of other variables were similar to those for educational hospitalization [23]. The estimates of Age, Comorbidities, Complications and Introduction dummy were positive and significant at the $1 \%$ level. This means that LOS was prolonged by age and complications. The LOS also became longer if patients came from another hospital. The estimate of After 2010 dummy was negative and significant at the 5\% level, and it was admitted that the 2010 revision reduced LOS. The estimates of the Female, 
Table 2. Results of estimation (LOS).

\begin{tabular}{|c|c|c|c|c|c|c|c|}
\hline Variable & Estimate & SE & t-value & Variable & Estimate & SE & t-value \\
\hline$\lambda$ & 0.4824 & 0.0010 & $485.31^{* *}$ & HP20 & 3.9390 & 0.2078 & $18.958^{* *}$ \\
\hline Female & 0.0286 & 0.0273 & 1.0477 & HP21 & 5.5099 & 0.2978 & $18.502^{* *}$ \\
\hline Age & 0.0053 & 0.0015 & $3.6228^{* *}$ & HP22 & 4.2774 & 0.1450 & $29.509^{* *}$ \\
\hline Age70 & -0.0403 & 0.0411 & -0.9807 & HP23 & 4.8487 & 0.2142 & $22.635^{* *}$ \\
\hline Comorbidities & 0.1170 & 0.0107 & $10.885^{* *}$ & HP24 & 4.0421 & 0.1669 & $24.219^{* *}$ \\
\hline Complications & 0.1675 & 0.0109 & $15.372^{* *}$ & HP25 & 4.9755 & 0.1567 & $31.754^{* *}$ \\
\hline Acute Hospitalization & 0.0574 & 0.0421 & 1.3622 & HP26 & 4.4978 & 0.1282 & $35.088^{* *}$ \\
\hline Outpatient & 0.0530 & 0.0432 & 1.2252 & HP27 & 4.4246 & 0.1478 & $29.943^{* *}$ \\
\hline Introduction & 0.1490 & 0.0325 & $4.5833^{* *}$ & HP28 & 4.2511 & 0.1890 & $22.489^{* *}$ \\
\hline Home & -0.0514 & 0.0373 & -1.3785 & HP29 & 4.5950 & 0.2458 & $18.692^{* *}$ \\
\hline Winter & -0.0441 & 0.0339 & -1.3034 & HP30 & 3.9840 & 0.1428 & $27.904_{* *}$ \\
\hline Summer & -0.0084 & 0.0333 & -0.2512 & HP31 & 5.2178 & 0.1451 & $35.956^{* *}$ \\
\hline One Week & -1.3904 & 0.032809 & $-42.378^{* *}$ & HP32 & 4.3233 & 0.1518 & $28.489^{* *}$ \\
\hline Over SHP & 4.6233 & 0.0533 & $86.739^{* *}$ & HP33 & 4.5857 & 0.1435 & $31.946^{* *}$ \\
\hline After 2010 & -0.1137 & 0.0557 & $-2.0419^{*}$ & HP34 & 3.5024 & 0.1309 & $26.765^{* *}$ \\
\hline Time & 0.0006 & 0.0023 & 0.2468 & HP35 & 4.6768 & 0.1993 & $23.464^{* *}$ \\
\hline ICD10 Dummies & & & & HP36 & 4.2679 & 0.1424 & $29.973^{* *}$ \\
\hline E112 & 0.0628 & 0.0594 & 1.0564 & HP37 & 4.4344 & 0.1366 & $32.459^{* *}$ \\
\hline E113 & 0.0634 & 0.0523 & 1.2118 & HP38 & 4.6163 & 0.1378 & $33.505^{* *}$ \\
\hline E114 & 0.0181 & 0.0748 & 0.2422 & НР39 & 5.3361 & 0.1381 & $38.653^{* *}$ \\
\hline E115 & 0.5088 & 0.1588 & $3.2028^{* *}$ & HP40 & 4.0143 & 0.1324 & $30.321^{* *}$ \\
\hline E116 & 0.1200 & 0.0491 & $2.4432^{*}$ & HP41 & 5.1711 & 0.1381 & $37.432^{* *}$ \\
\hline E117 & 0.1296 & 0.0351 & $3.6976^{* *}$ & HP42 & 4.6685 & 0.1094 & $42.656_{* *}$ \\
\hline Hospital Dummies & & & & HP43 & 4.5198 & 0.2189 & $20.648^{* *}$ \\
\hline HP1 & 4.4863 & 0.1169 & $38.367^{* *}$ & HP44 & 4.8467 & 0.1772 & $27.349^{* *}$ \\
\hline HP2 & 4.4642 & 0.1731 & $25.783^{* *}$ & HP45 & 4.7989 & 0.1255 & $38.226^{* *}$ \\
\hline HP3 & 4.5492 & 0.2039 & $22.316^{* *}$ & HP46 & 4.3817 & 0.1880 & $23.302^{* *}$ \\
\hline HP4 & 4.6349 & 0.1832 & $25.306^{* *}$ & HP47 & 4.4592 & 0.1442 & $30.922^{* *}$ \\
\hline HP5 & 4.8959 & 0.2677 & $18.288^{* *}$ & HР48 & 3.9485 & 0.1801 & $21.922^{* *}$ \\
\hline HP6 & 4.5489 & 0.1352 & $33.644^{* *}$ & HP49 & 4.8959 & 0.1100 & $44.524^{* *}$ \\
\hline HP7 & 4.9872 & 0.2066 & $24.134^{* *}$ & HP50 & 6.1109 & 0.1404 & $43.520^{* *}$ \\
\hline HP8 & 4.5842 & 0.1304 & $35.143^{* *}$ & HP51 & 4.8743 & 0.1902 & $25.624_{* *}$ \\
\hline HP9 & 5.0341 & 0.1516 & $33.214^{* *}$ & HP52 & 3.2377 & 0.1352 & $23.943^{* *}$ \\
\hline HP10 & 4.5405 & 0.2328 & $19.501^{* *}$ & HP53 & 4.9419 & 0.1401 & $35.265^{* *}$ \\
\hline HP11 & 4.0397 & 0.1738 & $23.238^{* *}$ & HP54 & 4.1868 & 0.1340 & $31.248^{* *}$ \\
\hline HP12 & 4.8730 & 0.1175 & $41.478^{* *}$ & HP55 & 5.0853 & 0.1720 & $29.569^{* *}$ \\
\hline HP13 & 4.5355 & 0.1493 & $30.379^{* *}$ & HP56 & 4.0793 & 0.1585 & $25.739^{* *}$ \\
\hline HP14 & 5.2492 & 0.1279 & $41.043^{* *}$ & HP57 & 5.0209 & 0.1491 & $33.685^{* *}$ \\
\hline HP15 & 4.6980 & 0.1367 & $34.365^{* * *}$ & HP58 & 3.7117 & 0.1815 & $20.450^{* *}$ \\
\hline HP16 & 4.6742 & 0.1888 & $24.755^{* *}$ & HP59 & 5.2332 & 0.1491 & $35.091^{* *}$ \\
\hline HP17 & 3.6085 & 0.1212 & $29.764^{* *}$ & HP60 & 4.8338 & 0.1995 & $24.227^{* *}$ \\
\hline HP18 & 4.0759 & 0.1557 & $26.174^{* * *}$ & R2 & & 0.5958 & \\
\hline HP19 & 4.4652 & 0.2330 & $19.161^{* *}$ & & & & \\
\hline
\end{tabular}

SE: Standard Error, ${ }^{*}$ Significant at the $5 \%$ level, ${ }^{* *}$ Significant at the $1 \%$ level. 
age 70, Acute Hospitalization, Outpatient, Home, Winter and Summer dummies were not significant at the 5\% level, and we could not find evidence that the LOS depended on these variables. The estimates of One Week and Over SHP dummies were positive and significant at the $1 \%$ level, showing that one-week hospitalization and exceeding the SHP affected LOS. With respect to the ICD-10 dummies, the estimates of E11.5 and E11.7 were positive and significant at the 1\%, as was E11.6 at the 5\% level; none of the other estimates was significant at the 5\% level. For the hospital dummies, the maximum estimate was 6.111 (HP50), the minimum was 3.238 (HP52), and the difference was 2.873 .

\subsection{Evaluation of DME}

Next, we evaluated daily medical expenditures $\left(D M E_{i j}\right)$ per patient. Since the distribution was not skewed, we used the OLS for the analysis of DME. Since heteroscedasticity of error terms might exist, the standard errors were obtained by the robust variance calculation method [34]. We considered the model given by

$$
\begin{aligned}
D M E_{i j}= & \beta_{1} \text { Female }+\beta_{2} \text { Age }+\beta_{3} \text { Age } 70+\beta_{6} \text { Comorbidities }+\beta_{5} \text { Complications } \\
& +\beta_{6} \text { Acute Hospitalization }+\beta_{7} \text { Outpatient }+\beta_{8} \text { Introduction }+\beta_{9} \text { Home }+\beta_{10} \text { LOS } \\
& +\beta_{11} \text { Over SHP }+\beta_{12} \text { Over SHP }(\text { LOS }- \text { SHP })+\sum_{\ell} \beta_{\ell} \text { ICD-10 dummy }+\sum_{i} \beta_{i} i \text {-th Hospital dummy }
\end{aligned}
$$

The medical expenditures of 129 patients were not available, and the DME of 42 were too low (below 10,000 yen). Excluding these patients, we used the dataset of 12,495 patients. The results of the estimation are presented in Table 3. The average daily medical expenditure (ADME) for regular patients was 27,375 yen, a little bit smaller than the ADME for educational hospitalization (27,983 yen) [24]. The estimates of Comorbidities and Complication were positive and significant at the $1 \%$ level. Thus, we found that comorbidities and complications not only made LOS longer but also DME higher. The estimates of Acute Hospitalization and Outpatients were significant at the $1 \%$ level but the signs were opposite. Acute hospitalization made DME higher but it were smaller if a patient was a hospital's own outpatient. The estimates of Winter and Summer were positive and significant at the $1 \%$ and $5 \%$ levels, respectively. In this case, we observed a seasonal effect. The estimate of After 2010 was positive and significant at the $1 \%$ level.

For the educational hospitalization case, the 2010 revision reduced DME, but we got the opposite result for regular patients. The estimate of LOS was negative and significant at the $1 \%$ level. Since daily payments to hospitals decrease as LOS becomes longer under the DPC/PDPS, this result is quite reasonable. On the other hand, estimates of Over SHP and Over SHP * (LOS - SHP) were positive and significant at the 1\% level. After the SHP, payment is based on a conventional fee-for-service system, and we got the same result as for the educational hospitalization cases. The coefficient time was negative and significant at the $1 \%$ level, and there was a time trend that reduced DME. Among the ICD-10 dummies, E11.2, E11.4 and E11.7 were positive at the 1\% or $5 \%$ levels, and the DME increased for these diseases. Among estimates of hospital dummies, the largest was 36,920 yen (HP28) and the smallest was 33,553 yen (HP49). The difference was 3368 yen or 12.3\% of the ADME of all patients.

\section{Discussion}

The analyses in the previous section suggest that the large differences of medical expenditures among hospitals were mainly caused by the ALOS. Moreover, large differences existed among hospitals, and the influence of the hospital was much larger than that of other variables. For example, let us consider two male patients staying at the same hospitals. One patient is age 80 , has 4 comorbidities and 4 complications, was introduced by another hospital, and has the ICD-10 code E11.7. The other patient is age 50, has no comorbidities or complications, was not introduced by another hospital, and has the ICD-10 code E11.9. (All other variables are set to the same values.) The former and later are the worst- and best-case scenario patients that we can consider. The difference of between these two patients is 1.534. The difference between the largest and smallest estimates of hospital dummies was 2.873, a much bigger number. Moreover, compared to the estimate of HP52 where the ALOS was the shortest, the estimates at 21 hospitals, more than one third of the total 60 hospitals, exceeded this criterion. This suggests that ALOS for some hospitals were unreasonably long, and it will be necessary for them to explain why and to revise their medical practices. It is difficult for the working generation to stay in a hospital for a long 
Table 3. Results of estimation (daily medical expenditure).

\begin{tabular}{|c|c|c|c|c|c|c|c|}
\hline Variable & Estimate & SE & t-value & Variable & Estimate & SE & t-value \\
\hline Female & -63.3 & 64.4 & -0.9822 & HP20 & 34,964 & 465 & $75.223^{* *}$ \\
\hline Age & 4.7 & 3.5 & 1.3594 & HP21 & 35,633 & 487 & $73.145^{* *}$ \\
\hline Age70 & -79.9 & 98.1 & -0.8144 & HP22 & 35,113 & 392 & $89.636^{* *}$ \\
\hline Comorbidities & 219.2 & 24.6 & $8.9076^{* *}$ & HP23 & 34,969 & 505 & $69.241^{* *}$ \\
\hline Complications & 196.7 & 26.3 & $7.4735^{* *}$ & HP24 & 34,820 & 364 & $95.705^{* *}$ \\
\hline Acute Hospitalization & 2464.7 & 88.3 & $27.897^{* *}$ & HP25 & 34,553 & 366 & $94.485^{* *}$ \\
\hline Own Outpatient & -342.7 & 95.3 & $-3.5951^{* *}$ & HP26 & 33,963 & 341 & $99.735^{* *}$ \\
\hline Another Hospital & -102.3 & 73.0 & -1.4010 & HP27 & 34,597 & 330 & $104.747^{* *}$ \\
\hline Home & -3.5 & 83.5 & -0.0419 & HP28 & 36,920 & 443 & $83.270^{* *}$ \\
\hline Winter & 242.1 & 79.1 & $3.0612^{* *}$ & HP29 & 35,302 & 475 & $74.358^{* *}$ \\
\hline Summer & 168.3 & 79.9 & $2.1052^{*}$ & HР30 & 33,617 & 336 & $100.148^{* *}$ \\
\hline After 2010 & 823.5 & 131.9 & $6.2443^{* *}$ & HP31 & 34,284 & 364 & $94.135^{* *}$ \\
\hline Over SHP & 1308.3 & 150.4 & $8.7014^{* *}$ & HP32 & 34,841 & 356 & $97.771^{* *}$ \\
\hline LOS & -443.2 & 6.0 & $-73.332^{* *}$ & НР33 & 35,537 & 382 & $93.087^{* *}$ \\
\hline Over SHP * (LOS-SHP) & 428.6 & 7.9 & $54.313^{* *}$ & HP34 & 35,817 & 378 & $94.847^{* *}$ \\
\hline Time & -97.4 & 5.4 & $-18.117^{* *}$ & HP35 & 34,376 & 517 & $66.493^{* *}$ \\
\hline ICD10 Dummies & & & & HР36 & 34,825 & 352 & $98.883^{* *}$ \\
\hline E112 & 474.0 & 133.2 & $3.5589^{* *}$ & HP37 & 34,371 & 366 & $93.966^{* *}$ \\
\hline E113 & -71.9 & 128.6 & -0.5588 & HР38 & 35,118 & 323 & $108.691^{* *}$ \\
\hline E114 & 330.4 & 151.8 & $2.1767^{*}$ & НР39 & 34,921 & 330 & $105.969^{* *}$ \\
\hline E115 & 169.6 & 360.3 & 0.4706 & HP40 & 33,847 & 315 & $107.344^{* *}$ \\
\hline E116 & 32.8 & 114.2 & 0.2874 & HP41 & 34,434 & 321 & $107.292^{* *}$ \\
\hline E117 & 274.7 & 83.8 & $3.2764^{* *}$ & HP42 & 35,276 & 288 & $122.294^{* *}$ \\
\hline Hospital Dummies & & & & HP43 & 34,455 & 435 & $79.254^{* *}$ \\
\hline HP1 & 35,750 & 294 & $121.678^{* *}$ & HP44 & 34,727 & 362 & $95.923^{* *}$ \\
\hline HP2 & 34,623 & 396 & $87.377^{* *}$ & HP45 & 34,694 & 328 & $105.928^{* *}$ \\
\hline HP3 & 35,780 & 459 & $77.946^{* *}$ & HP46 & 34,070 & 395 & $86.203^{* *}$ \\
\hline HP4 & 35,643 & 515 & $69.228^{* *}$ & HP47 & 34,603 & 348 & $99.309^{* *}$ \\
\hline HP5 & 36,026 & 448 & $80.364^{* *}$ & HP48 & 34,094 & 364 & $93.619^{* *}$ \\
\hline HP6 & 35,961 & 341 & $105.558^{* *}$ & HP49 & 33,553 & 281 & $119.418^{* *}$ \\
\hline HP7 & 34,220 & 438 & $78.150^{* *}$ & HP50 & 35,021 & 313 & $111.866^{* *}$ \\
\hline HP8 & 34,820 & 340 & $102.329^{* *}$ & HP51 & 34,695 & 372 & $93.172^{* *}$ \\
\hline HP9 & 33,968 & 392 & $86.757^{* *}$ & HP52 & 35,681 & 334 & $106.946^{* *}$ \\
\hline HP10 & 35,554 & 495 & $71.846^{* *}$ & HP53 & 35,127 & 336 & $104.581^{* *}$ \\
\hline HP11 & 34,862 & 425 & $81.970^{* *}$ & HP54 & 34,669 & 355 & $97.524^{* *}$ \\
\hline HP12 & 34,361 & 308 & $111.477^{* *}$ & HP55 & 33,833 & 428 & $78.982^{* *}$ \\
\hline HP13 & 34,518 & 383 & $90.128^{* *}$ & HP56 & 35,708 & 343 & $104.226^{* *}$ \\
\hline HP14 & 35,810 & 310 & $115.561^{* *}$ & HP57 & 34,514 & 374 & $92.168^{* *}$ \\
\hline HP15 & 34,792 & 364 & $95.640_{* *}$ & HP58 & 36,856 & 482 & $76.479^{* *}$ \\
\hline HP16 & 36,048 & 435 & $82.873^{* *}$ & HP59 & 35,020 & 359 & $97.503^{* *}$ \\
\hline HP17 & 36,121 & 290 & $124.763^{* *}$ & HP60 & 33,703 & 443 & $76.027^{* *}$ \\
\hline HP18 & 35,510 & 404 & $87.805^{* *}$ & $\mathrm{R} 2$ & & 0.4847 & \\
\hline HP19 & 34,072 & 489 & $69.699^{* *}$ & & & & \\
\hline
\end{tabular}

S E: Standard Error, ${ }^{*}$ Significant at the $5 \%$ level, ${ }^{* *}$ Significant at the $1 \%$ level. 
period of time (two weeks or more). Therefore, long LOS might prevent working-age patients in the early stages of diabetes from getting proper treatments. The Japanese standard retirement age is 65, and the average age of patients was 64 , with more than half of patients aged 65 or younger.

On the other hand, the differences of ADME among hospitals were relatively small. After eliminating the influence of patient characteristic and conditions, the differences between the maximum and minimum were only $12 \%$ of the overall average.

The estimate of Over SHP dummy was 4.623, very large compared to other non-hospital dummy variables. Once LOS exceeded the SHP, patients stayed in hospitals for long periods of time. Eleven percent of patients, not a small number, stayed over the SHP, and ALOS for these patients was 44.6 days. Payment is based on a conventional fee-for-service system after the SHP, and our analyses revealed that the DME did not decrease after the SHP. In other words, there is no incentive for hospitals to discharge patients earlier under the current DPC/PDPS. Therefore, new incentives for high and efficient quality medical services [35] [36] may be necessary to improve the DPC/PDPS in future revisions.

In our dataset, only 131 regular patients out of 14,193 were reported as complete recoveries; that is, at least 99\% of patients required medical care after leaving the hospital. Moreover, a large number of patients do not follow prescribed therapies [37]. Dilla et al. [38] reported that it was possible to control medical expenses by reducing body mass index (BMI). Although compared to non-diagnosed individuals at risk for high blood sugar, diagnosed diabetics are more likely to improve their lifestyle, the effect diminishes and some behavioral responses to diabetes may be short-lived [39]. Therefore, systems that take proper care of patients for long periods of time after hospitalization are absolutely necessary for diabetes. However, such systems are not yet sufficiently established [22], and we need to institute them as soon as possible. For the development of new systems, adoption of health-information technologies [40] and proper budget allocation [41] are considered critically important. The differences of social and cultural factors should also be considered. Condliffe and Link [42] found that medical expenditures were different among races. Phelps, Hodgson and Lamson [43] suggested that it is necessary to consider ethnic group differences. Salois [44] pointed out that a "local" food economy might be an important factor in the prevention of obesity and diabetes. Finally, Pan and Ward [45] suggested the necessity of developing models to explain the relationship between self-related health and diabetes self-management in a non-Western context. In establishing desirable systems, these factors should also be considered.

\section{Conclusions}

In this paper, we consider an analysis of the LOS and daily medical expenditure (DME) for regular patients with type 2 diabetes. LOS was analyzed by the power Box-Cox transformation model when variances differed among hospitals. We proposed a new test and consistent estimator. We rejected the homoscedasticity of variances among hospitals, and the feasibility of the proposed model was strongly supported. We then analyzed the LOS of 12,666 type 2 diabetes regular patients collected from 60 DPC hospitals in Japan. The variables found to affect LOS were age, number of comorbidities and complications, introduced by another hospital, one-week hospitalization, 2010 revision, Specific-Hospitalization-Period (SHP), and principal diseases E11.5, E11.6 and E11.7. There were surprisingly large differences in ALOS among hospitals even after eliminating the influences of characteristics and conditions of patients.

We then analyzed the DME by the OLS method. The variables that affected DME were LOS, number of comorbidities and complications, acute hospitalization, hospital's own outpatient, season, introduced by another hospital, one-week hospitalization, 2010 revision, SHP, LOS, time trend, and principal diseases E11.2, E11.4 and E117. The DME did not decrease after the SHP. After eliminating the influence of characteristics and conditions of patients, the differences among hospitals were relatively small, $12 \%$ of the overall average. Since at least $99 \%$ of patients require medical care after leaving the hospital, systems designed to properly care for patients over long periods of time after hospitalization are absolutely necessary for diabetes.

Diabetes is a chronic disease and a long-term evaluation for medical expenditures and outcomes of treatments is necessary. Eggleston et al. [46] analyzed the data of 821 patients joining a self-funded health plan between 1999 and 2009 and concluded that the unit cost of treatment for diabetes, adjusting for the value of health outcomes, has been roughly constant over time. Thurecht and Brown [47] developed a diabetes simulation model that could provide a wide range of outputs to assess the current and projected impact of those with the disease in Australia. Such analyses are also necessary in Japan. Although type 1 diabetes was not analyzed in this study, it 
is also an important factor for controlling the costs of diabetes [48]. These are subjects to be analyzed in future studies.

\section{Acknowledgements}

The Institutional Review Boards of the University of Tokyo (number: KE12-7) and Tokyo Medical and Dental University (number: 839) approved the use of this dataset. We would like to thank an anonymous referee and Prof. Yoko Ibuka at the Tohoku University for their helpful comments and suggestions.

\section{References}

[1] Ministry of Health, Labour and Welfare (2015) Hesiei 25 nendo kokumin iryouhi (National Medical Expenditures, Fiscal Year 2013, in Japanese).

[2] Ministry of Finance (2015) Kuni oyobi chihou no chouki saimu sandaka (Long-Term Deficits of the Central and Local Governments, in Japanese).

[3] International Diabetes Foundation (2014) DIABETES ATLAS. 6th Edition. http://www.idf.org/sites/default/files/Atlas-poster-2014 EN.pdf

[4] American Diabetes Association ADA (2015) Complications. http://www.diabetes.org/

[5] Alva, M., Gray, A., Mihayalov, B. and Clarke, P. (2014) The Effect of Diabetes Complications on Health-Related Quality of Life: The Longitudinal Data to Address Patient Heterogeneity. Health Economics, 23, 487-500. http://dx.doi.org/10.1002/hec.2930

[6] Public Health Agency of Canada (2015) The Health and Economic Impacts of Diabetes. Chapter 3, Diabetes in Canada: Facts from a Public Health Perspective. http://www.phac-aspc.gc.ca/cd-mc/publications/diabetes-diabete/facts-figures-faits-chiffres-2011/chap3-eng.php

[7] Lesniowska, J., Schubert, A., Wojna, M., et al. (2014) Costs of Diabetes and Its Complications in Poland. European Journal of Health Economics, 15, 653-660. http://dx.doi.org/10.1007/s10198-013-0513-0

[8] Chereches, R.M., Litan, C.M., Zlati, A.M. and Bloom, J.R. (2012) Does Co-Morbid Depression Impact Diabetes Related Costs? Evidence from a Cross-Sectional Survey in a Low-Income Country. Journal of Mental Health Policy and Economics, 15, 127-138.

[9] Yeaw, J. (2014) Direct Medical Costs for Complications among Children and Adults with Diabetes in the US Commercial Setting. Applied Health Economics and Health Policy, 12, 219-230. http://dx.doi.org/10.1007/s40258-014-0086-9

[10] Zhuo X., Zhang, P., Barker, L., et al. (2014) The Lifetime Cost of Diabetes and Its implications for Diabetes Prevention. Diabetes Care, 37, 2557-2564. http://dx.doi.org/10.2337/dc13-2484

[11] Condliffe, S., Link, C.R., Parasuraman, S. and Pollack, M.F. (2013) The Effects of Hypertension and Obesity on Total Health-Care Expenditures of Diabetes Patients in the United States. Applied Economics Letters, 20, 649-652. http://dx.doi.org/10.1080/13504851.2012.727966

[12] Yesudian, C.A.K., Grepstad, M., Visintin, E. and Ferrario, A. (2014) The Economic Burden of Diabetes in India: A Review of the Literature. Globalization and Health, 10, 80. http://dx.doi.org/10.1186/s12992-014-0080-x

[13] Dall, T.M., Zhang, Y., Chen, Y.J., Quick, W.W., Yang, W.G. and Fogli, J. (2010) The Economic Burden of Diabetes. Health Affairs, 29, 297-303. http://dx.doi.org/10.1377/hlthaff.2009.0155

[14] American Diabetes Association (ADA) (2013) Economic Costs of Diabetes in the U.S. in 2012. Diabetes Care, 36, 1033-1046. http://dx.doi.org/10.2337/dc12-2625

[15] Minor, T. (2011) The Effect of Diabetes on Female Labor Force Decision: New Evidence from the National Health Interview Survey. Health Economics, 20, 1468-1486. http://dx.doi.org/10.1002/hec.1685

[16] Minor, T. (2013) An Investigation into the Effect of Type I and Type II Diabetes Duration on Employment and Wages. Economics and Human Biology, 11, 534-544. http://dx.doi.org/10.1016/j.ehb.2013.04.004

[17] Sørensen, J. and Ploug, U.J. (2013) The Cost of Diabetes-Related Complications: Registry-Based Analysis of Days Absent from Work. Economic Research International, 2013, Article ID: 618039. http://dx.doi.org/10.1155/2013/618039

[18] Liu, X. and Zhub, C. (2014) Will Knowing Diabetes Affect Labor Income? Evidence from a Natural Experiment. Economics Letters, 124, 74-78. http://dx.doi.org/10.1016/j.econlet.2014.04.019

[19] Seuring, T., Goryakin, Y. and Suhrcke, M. (2015) The Impact of Diabetes on Employment in Mexico. Economics and Human Biology, 18, 85-100. http://dx.doi.org/10.1016/j.ehb.2015.04.002 
[20] DPC Evaluation Division, Central Social Insurance Medical Council, Ministry of Health, Labour and Welfare (2015) DPC taishou byouin, junnbi byouin no kibo (heisei 27 nen 4 gatsu 1 nichi) mikomi [Estimated Numbers of DPC Hospitals and Preparing Hospitals by Sizes of Hospitals as of April 1st, 2015]. (In Japanese)

[21] IDF (2014) About Diabetes. http://www.idf.org/about-diabetes

[22] ADA (2015) Diabetes Basic. http://www.diabetes.org/

[23] Nawata, K. and Kawabuchi, K. (2015) Evaluation of Length of Hospital Stay Joining Educational Programs for Type 2 Diabetes Mellitus Patients: Can We Control Medical Costs in Japan? Health, 7, 256-269. http://dx.doi.org/10.4236/health.2015.72030

[24] Nawata, K. and Kawabuchi, K. (2015) Financial Sustainability of the Japanese Medical Payment System: Analysis of the Japanese Medical Expenditure for Educational Hospitalization of Patients with Type 2 Diabetes. Health 7, 10071021. http://dx.doi.org/10.4236/health.2015.78118

[25] Box, G.E.P. and Cox, D.R. (1964) An Analysis of Transformation. Journal of the Royal Statistical Society B, 26, 211-252.

[26] Showalter, M.H. (1994) A Monte Carlo Investigation of the Box-Cox Model and a Nonlinear Least Squares Alternative. Review of Economics and Statistics, 76, 560-570. http://dx.doi.org/10.2307/2109980

[27] Nawata, K. (2015) Robust Estimation Based on the Third-Moment Restriction of the Error Terms for the Box-Cox Transformation Model: An Estimator Consistent under Heteroscedasticity. Economics Bulletin, 3, 1056-1064.

[28] Heinze, G., Hronsky, M., Reichardt, B., Baumgärtel, C., Müllner, M., Bucsics, A. and Winkelmayer, W.C. (2015) Potential Savings in Prescription Drug Costs for Hypertension, Hyperlipidemia, and Diabetes Mellitus by Equivalent Drug Substitution in Austria: A Nationwide Cohort Study. Applied Health Economics and Policy, 13, 193-205. http://dx.doi.org/10.1007/s40258-014-0143-4

[29] Watson, P., Preston, L., Squires, H., Chilcott, J. and Brennan, A. (2014) Modelling the Economics of Type 2 Diabetes Mellitus Prevention: A Literature Review of Methods. Applied Health Economics and Health Policy, 12, 239-253. http://dx.doi.org/10.1007/s40258-014-0091-z

[30] Sittig, D.T., Friedel, H. and Wasem, J. (2015) Prevalence and Treatment Costs of Type 2 Diabetes in Germany and the Effects of Social and Demographical Differences. European Journal of Health Economics, 16, 305-311. http://dx.doi.org/10.1007/s10198-014-0575-7

[31] Bickel, P.J. and Doksum, K.A. (1981) An Analysis of Transformations Revisited. Journal of the American Statistical Association, 76, 296-311. http://dx.doi.org/10.1080/01621459.1981.10477649

[32] Nawata, K. (2013) A New Estimator of the Box-Cox Transformation Model Using Moment Conditions. Economics Bulletin, 33, 2287-2297.

[33] Hausman, J. (1978) Specification Tests in Econometrics. Econometrica, 46, 1251-1272. http://dx.doi.org/10.2307/1913827

[34] White, H. (1980) A Heteroskedasticity-Consistent Covariance Matrix and Direct Test for Heteroskedasticity. Econometrica, 48, 817-838. http://dx.doi.org/10.2307/1912934

[35] Kantarevic, J. and Kralj, B. (2013) Link between Pay for Performance Incentives and Physician Payment Mechanisms: Evidence from Diabetes Management Incentive in Ontario. Health Economics, 22, 1417-1439. http://dx.doi.org/10.1002/hec.2890

[36] Iezzi, E., Bruni, M.L. and Ugolini, C. (2014) The Role of GP’s Compensation Schemes in Diabetes Care: Evidence from Panel Data. Journal of Health Economics, 34, 104-120. http://dx.doi.org/10.1016/j.jhealeco.2014.01.002

[37] Wilke, T., Groth, A., Mueller, S., Reese, D., Linder, R., Ahrens, S. and Verheyen, F. (2013) How to Use Pharmacy Claims Data to Measure Patient Nonadherence? The Example of Oral Diabetics in Therapy of Type 2 Diabetes Mellitus. European Journal of Health Economics, 14, 551-568. http://dx.doi.org/10.1007/s10198-012-0410-y

[38] Dilla, T., Valladares, A., Nicolay, C., Salvador, J., Reviriego, J. and Costi, M. (2012) Healthcare Costs Associated with Change in Body Mass Index in Patients with Type 2 Diabetes Mellitus in Spain: The ECOBIM Study. Applied Health Economics and Policy, 10, 417-430. http://dx.doi.org/10.1007/BF03261876

[39] Slade, A.N. (2012) Health Investment Decisions in Response to Diabetes Information in Older Americans. Journal of Health Economics, 31, 502-520. http://dx.doi.org/10.1016/j.jhealeco.2012.04.001

[40] Daim, T.U., Basoglu, N. and Topacan, U. (2013) Adoption of Health Information Technologies: The Case of a Wireless Monitor for Diabetes and Obesity Patients. Technology Analysis \& Strategic Management, 25, 923-938. http://dx.doi.org/10.1080/09537325.2013.823150

[41] Mehrotra, S. and Kim, K. (2011) Outcome Based State Budget Allocation for Diabetes Prevention Programs Using Multi-Criteria Optimization with Robust Weights. Health Care Management Science, 14, 324-337. http://dx.doi.org/10.1007/s10729-011-9166-7 
[42] Condliffe, S. and Link, C.R. (2014) Racial Differences in the Effects of Hypertension and Obesity on Health Expenditures by Diabetes Patients in the US. Applied Economics Letters, 21, 280-283. http://dx.doi.org/10.1080/13504851.2013.856990

[43] Phelps, K.W., Hodgson, J.L. and Lamson, A.L. (2012) Satisfaction with Life and Psychosocial Factors among Underserved Minorities with Type 2 Diabetes. Social Indicators Research, 106, 359-370. http://dx.doi.org/10.1007/s11205-011-9811-z

[44] Salois, M.J. (2012) Obesity and Diabetes, the Built Environment, and the "Local” Food Economy in the United States, 2007. Economics and Human Biology, 10, 35-42. http://dx.doi.org/10.1016/j.ehb.2011.04.001

[45] Pan, X. and Ward, R.M. (2015) Self-Management and Self-Rated Health among Middle-Aged and Older Adults with Type 2 Diabetes in China: A Structural Equation Model. Social Indicators Research, 120, 247-260. http://dx.doi.org/10.1007/s11205-014-0575-0

[46] Eggleston, K.N., Shah, N.D., Smith, S.A., Berndt, E.R. and Newhouse, J.P. (2011) Quality Adjustment for Health Care Spending on Chronic Disease: Evidence from Diabetes Treatment, 1999-2009. American Economic Review: Papers \& Proceedings, 101, 206-211. http://dx.doi.org/10.1257/aer.101.3.206

[47] Thurecht, L. and Brown, L. (2011) Economic Modelling of the Prevention of Type 2 Diabetes in Australia-The Diabetes Model. International Journal of Microsimulation, 4, 71-80.

[48] Kruger, J. and Brennan, A. (2013) The Cost of Type 1 Diabetes Mellitus in the United Kingdom: A Review of Cost-of-Illness Studies. European Journal of Health Economics, 14, 886-899.

http://dx.doi.org/10.1007/s10198-012-0433-4 